\title{
Performance Improvement of a Typical Manifold using Computational Fluid Dynamics
}

\author{
N. Subaschandar*, G. Sakthivel ${ }^{\#}$ \\ *Department of Mathematics and Computational Sciences, BIUST, Palapye, Botswana \\ \#COMMAIR, Osborne Park, WA , Australia
}

\begin{abstract}
This paper presents an analysis of fluid flow in a typical manifold. A commercially available Computational Fluid Dynamics (CFD) package has been used to analyze the flow pattern inside the manifold. Pressure drop in whole fluid domain and mass flow rate in all the outlets in the manifold have been computed. Based on the preliminary results, a modification to inside of the main pipe of the manifold has been incorporated. The performance of the modified design has been compared with the original design from the point of view of average temperature and mass flow rate at the outlets. A simple modification has been shown to improve the uniformity of temperature and mass flow at the outlets.
\end{abstract}

\section{Introduction}

Flow in manifold is of great importance in many industrial processes when it is necessary to distribute a large fluid stream into several smaller streams and then to collect them into one discharge stream. Flow inside a manifold in which two or more fluids with different velocities, temperatures and/or concentrations are mixed is encountered in various thermal and industrial equipment, e.g., chemical reactor, combustion chamber, piping system in power plants. The flow in manifolds is extensively encountered in many industrial processes when it is necessary to distribute a large fluid stream into several parallel streams and then to collect them into one discharge stream, such as fuel cells, plate heat exchanger, radial flow reactor, and irrigation. One of the typical mixing manifolds is found in the HVAC (Heating, Ventilating, Air-conditioning) systems. The flow field in the mixing manifold is accompanied by the flow separation and reattachment, secondary flow, and strong turbulence. Therefore, it is expected that the turbulent fluid, heat and mass transport processes between the hot and cold flows is quite complex. In order to develop effective methods of the mixing promotion and control, one has to fully understand the detailed flow characteristics and mechanism of the mixing of flows in the manifold. For most applications, the goal of manifold design is to achieve a uniform flow distribution through all of the lateral exit ports. A great number of experimental, analytical, and numerical studies deal with flow in manifold. The flow in distribution manifold has been studied by several investigators [1-9]. In general, all previous studies for manifolds with different applications had shown that typical manifold design does not give a uniform flow distribution at outlets. Therefore, the objective of the present study was to predict the flow distribution through each outlet and to develop an optimized design having a better flow distribution through outlets. The purpose of this analysis is to establish the influence of the inflow velocity (flow rate) along uniformity of the exit flows through the multiple holes. This work focuses on the prediction of pressure drop in the main stream which affects the mass flow rate of the gas flowing out through the outlet holes. Computational fluid dynamics methodology has been used to analyse the manifold geometry.

\section{Computational fluid dynamics model}

The model studied here is shown in Figure 1. It is a simple manifold with two inlet pipes. One inlet pipe is at the top and cold water is passed through this inlet. The second inlet pipe is in the horizontal orientation joining the main pipe at about half the height from the top. Hot water is passed through this inlet pipe. There are four outlet holes in the bottom horizontal pipe section through which the mixed water goes out. The diameter and length of the horizontal pipe at the bottom are $40 \mathrm{~mm}$ and $300 \mathrm{~mm}$. The diameter and length of the vertical pipe is $30 \mathrm{~mm}$ and $400 \mathrm{~mm}$ respectively. The small horizontal pipe through which hot water is passed through has diameter of $30 \mathrm{~mm}$ and a length of $40 \mathrm{~mm}$. The diameter of the four outlets at the bottom horizontal pipe are same $(5 \mathrm{~mm})$. The models were built and CFD analysis was made using the commercially available software SOLIDWORKS. In the preliminary study, the original 
geometry of the manifold is analysed. The Table 1 gives the inlet and outlet conditions for all computations.

Table 1 : Conditions at the inlet pipe and outlet pipe.

\begin{tabular}{|c|c|c|c|}
\hline Boundary & $\begin{array}{c}\text { Mass flow } \\
\text { rate(Kg/s) }\end{array}$ & $\begin{array}{c}\text { Temp } \\
\left({ }^{0} \mathrm{C}\right)\end{array}$ & Pressure \\
\hline $\begin{array}{c}\text { Cold } \\
\text { Water Inlet }\end{array}$ & 1.0 & 20 & \\
\hline $\begin{array}{c}\text { Hot water } \\
\text { Inlet }\end{array}$ & 0.4 & 80 & \\
\hline Outlets & - & - & $\begin{array}{c}\text { Atmospheric } \\
\text { Pressure }\end{array}$ \\
\hline
\end{tabular}

Figure 2 shows a typical grid used for computation for the original geometry. Original geometry had about 126,000 cells in the computational domain. In all subsequent computations, the grid size was kept around 126,000 so as to avoid the influence of grid size while comparing the results. K- $-\varepsilon$ turbulence model is used for all computations.

\section{Results and Discussion}

Figures $3 \mathrm{a}, 3 \mathrm{~b}$ and $3 \mathrm{c}$ show the contours of static pressure, velocity and temperature inside the manifold model. From these figures one can see that non-uniformity exists in the exit planes.

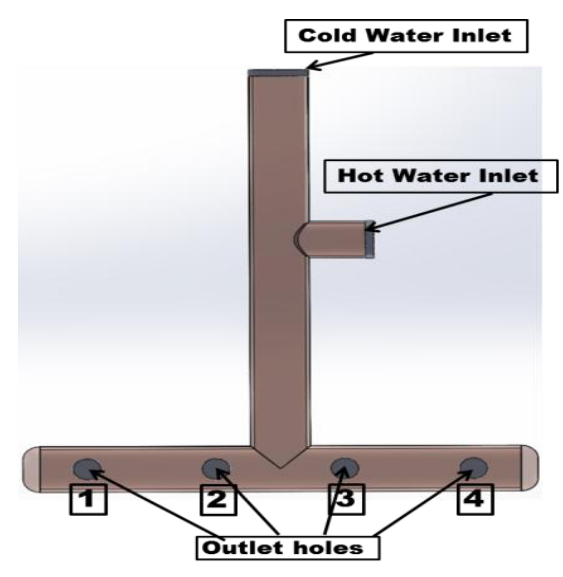

Figure 1 Original geometry with inlet pipes and outlets shown

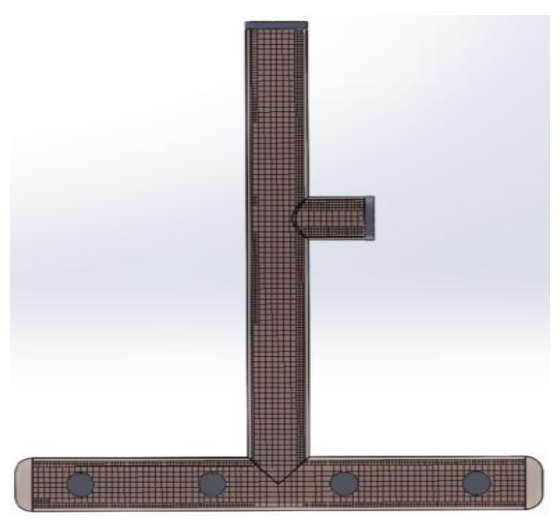

Figure 2 Typical grid inside the computational domain

From Figure $3 \mathrm{c}$ we can see that hot water and cold water do not mix evenly and, almost, both the streams are separated. It was observed that the existence of nonuniformity at the outlets is mainly due to non-mixing of cold and hot water streams. Based on these preliminary results of the original geometry, a design modification was carried out. Two humps were placed in the vertical pipe below the hot water inlet pipe on both sides as shown in Figure 4. Both humps are in the flow direction, having a length of $35 \mathrm{~mm}$, giving minimum disturbance to the flow. Humps extend upto the centreline of the vertical pipe.
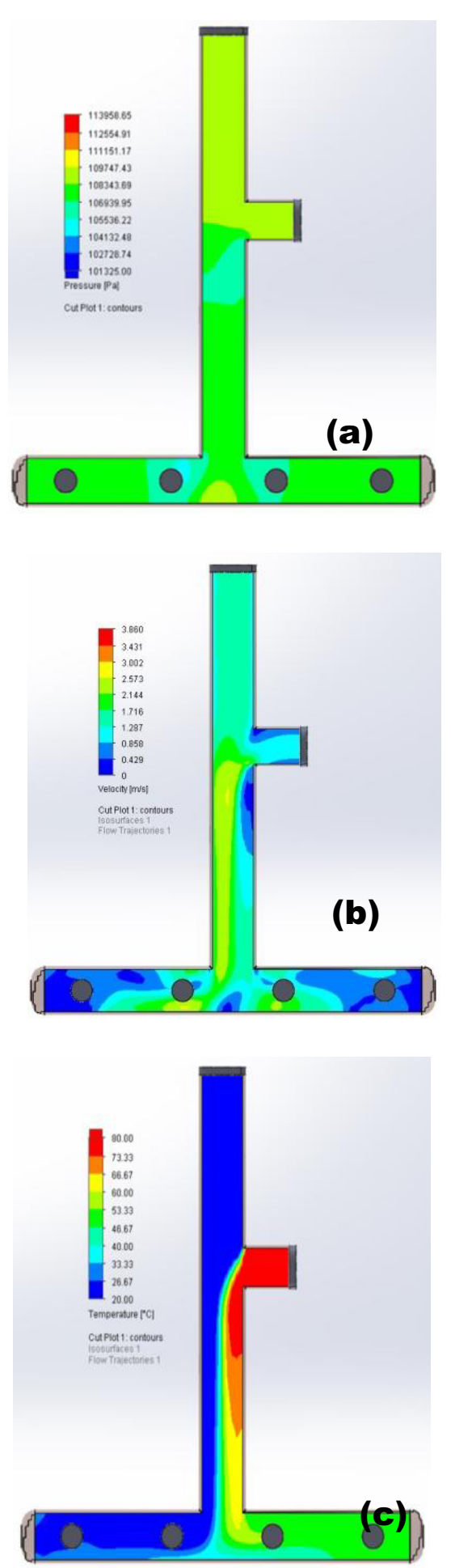

Figure 3 Contours of (a) Pressure, (b) Velocity and (c) Temperature inside the manifold for the original model 


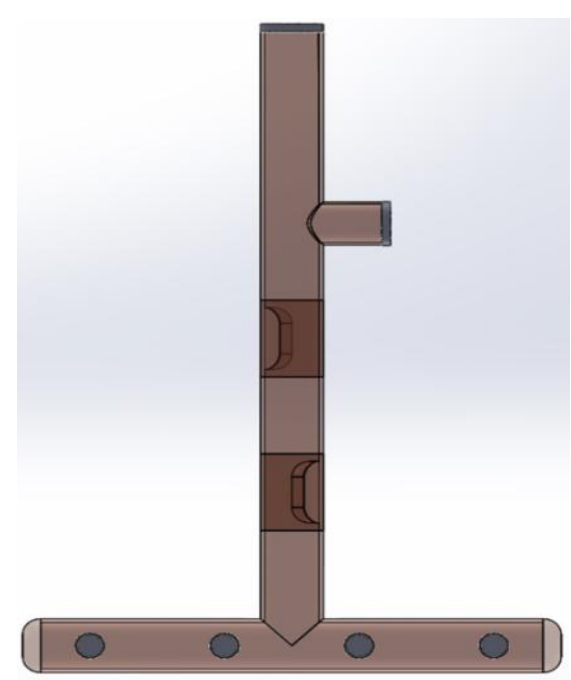

Figure 4 Modified geometry with two humps inside the vertical pipe.
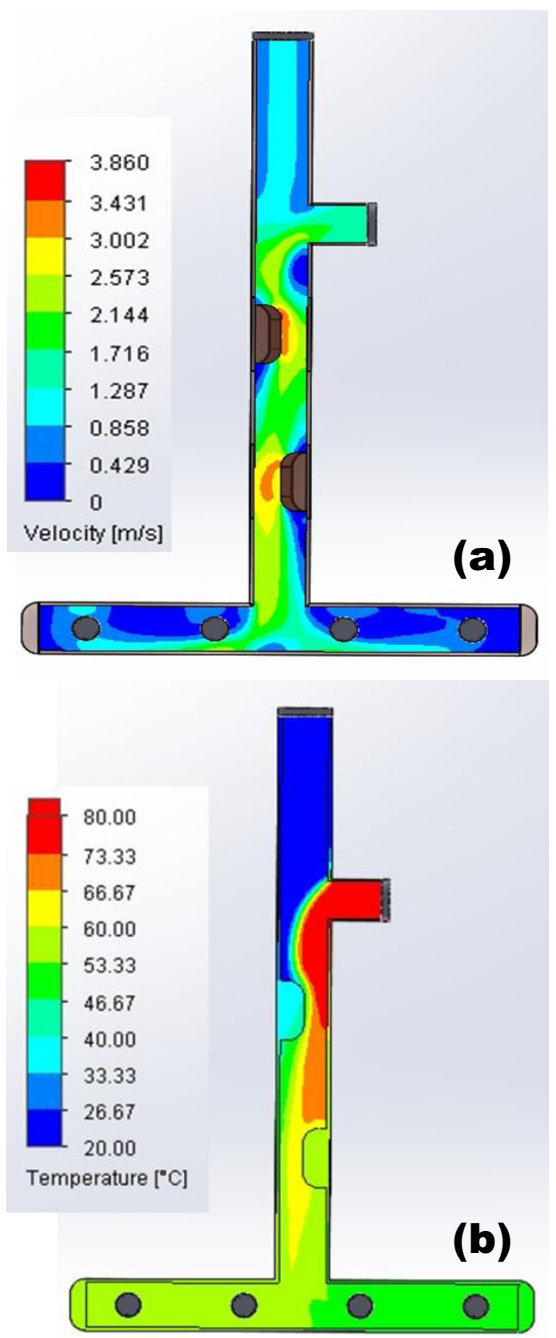

Figure 5 Velocity(a) and temperature(b) contours inside modified manifold geometry

The modified geometry was analysed using computational fluid dynamics method. Figures $5 \mathrm{a}$ and $5 \mathrm{~b}$ show the contours of velocity and temperature inside the manifold. As we can see from these figures that the velocity and temperature are more evenly distributed and there is proper mixing of cold and hot water at the outlets. Table 2 gives the mass flow rates and temperature at the four outlets for both original and modified geometries. From this Table 2, also, we see that mass flow rate and temperature values are almost equal in all the four outlets. Here Mass flow rate has been expressed as a percentage of total mass flow rate of fluids passing through both inlet pipes. Figure 6 gives the contours of temperature distribution inside the manifold for both original and modified geometry for comparison. This figure clearly shows the effect of design modification carried out in improving the flow quality and flow uniformity at the outlets.

Table 2 : Mass flow rates and Temperatures at the four outlets for the modified geometry

\begin{tabular}{|c|c|c|c|c|}
\hline & \multicolumn{2}{|c|}{ Original Model } & \multicolumn{2}{c|}{ Modified Model } \\
\hline \multirow{3}{*}{ Outlet } & $\begin{array}{c}\text { Mass } \\
\text { Flow } \\
\text { Rate } \%\end{array}$ & $\begin{array}{c}\text { Mass } \\
\text { Flow }\left({ }^{0} \mathrm{C}\right)\end{array}$ & $\begin{array}{c}\text { Flow } \\
\text { Rate } \%\end{array}$ & Temp $\left({ }^{0} \mathrm{C}\right)$ \\
\hline 1 & 28.82 & 27.24 & 25.61 & 51.39 \\
\hline 2 & 20.48 & 23.03 & 24.91 & 50.55 \\
\hline 3 & 21.76 & 51.36 & 23.77 & 53.24 \\
\hline 4 & 28.94 & 46.54 & 25.71 & 56.09 \\
\hline
\end{tabular}

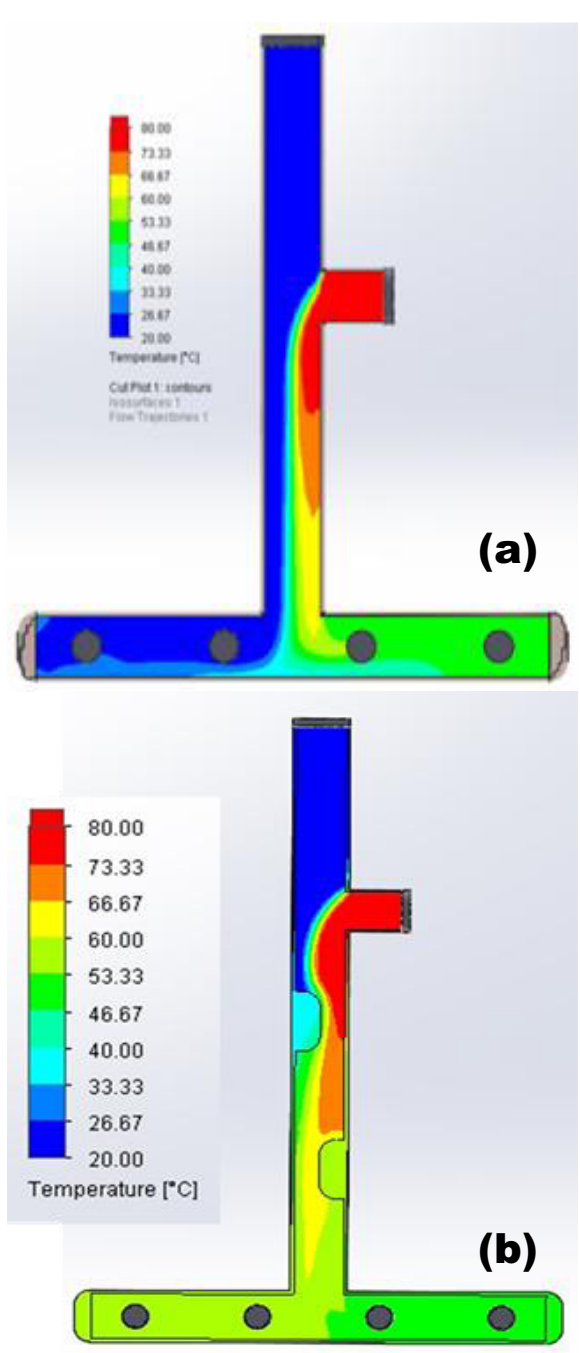

Figure 6 Contours of temperature inside the manifold for (a) Original model, (b) Modified model 


\section{Conclusions}

Computational fluid dynamics methodology has been used to analyse the flow characteristics inside a manifold. The original geometry is found to have flow non uniformity in terms of mass flow rates and temperatures at the outlets. It is shown that hot water and cold water streams were, almost, not mixing inside the manifold, causing the maldistributions in mass flow rates and temperatures in the outlets. Based on the preliminary results a design modification has been implemented by adding two humps in the vertical pipe along the flow direction. Results show that the maldistribution at the outlets for mass flow rate and temperatures has decreased significantly. It is shown that this simple design modification has improved the flow quality by giving nearly equal mass flow rates and temperatures at the outlets. It has been shown that the computational fluid dynamics methodology can be used effectively and successfully to analyse and improve flow quality inside a manifold.

\section{Acknowledgements}

Author acknowledges the support rendered by Department of Mathematics and Computational Sciences, BIUST, Botswana in carrying out this research.

\section{References}

1. M. S. Gandhi, A. A. Ganguli, J. B. Joshi, and P. K. Vijayan, Chemical Engineering Research and Design, 90, 487 (2012).

2. R. A. Bajura, J. of Engng for Gas Turbines and Power, 93, 7, (1971).

3. R. A. Bajura and E. H. Jones Jr., J. of Fluids Engng, Transactions of the ASME, 98, 4, 654 (1976).

4. A. K. Majumdar, Applied Mathematical Modelling, 4, no. 6, 424 (1980).

5. M. K. Bassiouny and H. Martin, Chemical Engineering Science, 39, no. 4, 693 (1984).

6. M. K. Bassiouny, H. Martin, Chemical Engineering Science, 39, 4, 701(1984).

7. J. S. McNown, Transactions of ASCE, 119, 1103 (1954).

8. A. Acrivos, B. D. Babcock, and R. L. Pigford, Chemical Engineering Science, 10, 112 (1959).

9. R. L. Pigford, M. Ashraf, and Y. D. Mlron, Ind. Eng. Chem. Fundam. 22, 463 (1983). 